\title{
Malignant Melanoma and Pregnancy
}

\author{
Hanne Stensheim \\ Cancer Registry of Norway, Oslo, Norway
}

Malignant melanoma is a major cause of cancer death among women of childbearing age. It is one of the most common cancer types diagnosed during pregnancy, besides breast cancer and cervical cancer. The coincidence of cancer and pregnancy is increasing, as women today postpone childbearing and cancer incidence is rising. Of 1000 pregnancies, $0.1-2.8$ are reported complicated with malignant melanoma [1], although it appears to vary geographically and/or with skin type. Worth noticing is that most studies concern incidence of melanomas diagnosed during pregnancy, but some even include cases 12 months post-partum.

As referred in the article 'Advanced metastatic melanoma in pregnancy: a multidisciplinary challenge' published in this number of ONKOLOGIE [2], $8 \%$ of all cancers during pregnancy are malignant melanomas. In 2 Nordic population-based studies, much higher incidences were found, $31 \%$ in the Norwegian and a similar number in the Swedish study, which might reflect the general high incidence of malignant melanoma in the more fair-skinned population of Scandinavia [3, 4].

In the case report in this issue, the patient was already diagnosed 2.5 years before her pregnancy with a malignant melanoma stage II and Clark level IV, and she was receiving systemic therapy because of metastatic disease when she became pregnant. During her pregnancy, also liver and bone metastases were detected. A small but healthy baby was delivered before gestational week 29 by a planned Caesarian section. The patient, however, died within 3 months. A multidisciplinary team followed the patient and her unborn child by weekly conferences, to optimize the treatment and management for both. It is not mentioned whether she did undergo a sentinel lymph node biopsy at diagnosis, and it remains unclear whether she was advised against becoming pregnant while she was receiving interferon alpha. The multidisciplinary management is underscored and appears to reflect good medical care both for the mother and the fetus, attending to the challenging situation at an individual or family basis, like recommended.
Survival for pregnant women diagnosed with malignant melanoma during pregnancy has represented a controversy at least since the 1950s. The disease was previously considered hormone related and therefore thought to be influenced by the high estrogen levels during pregnancy. Several uncontrolled case-series have demonstrated poorer survival for women with pregnancy-associated melanomas [5-6]. More recently published controlled studies show that initial tumor thickness seems to be the only important prognostic factor, possibly besides tumor site. Three retrospective populationbased studies have failed to demonstrate that survival is different for pregnant women compared to non-pregnant controls $[3,7,8]$. Several case-control studies and case series have been published since the mid-1980s, and 6 well-controlled studies all conclude that similar survival is observed for pregnant women with malignant melanoma stage I or II and non-pregnant women with similar disease characteristics [9-14]. Somewhat shorter disease-free intervals in pregnant women were found by Reintgen and Slinguff, who also had overlapping patient populations $[9,12]$. As of today, there is no real evidence suggesting that pregnancy-induced hormonal changes have an adverse effect on survival in women diagnosed with melanoma during pregnancy. Neither the use of oral contraceptives nor hormone replacement therapy has been found to worsen the prognosis $[15,16]$.

For women with subsequent pregnancies after malignant melanoma, the overall prognosis is good [3, 7]. This might, however, be a selected group of women with initially low stage tumors, who have opted to become pregnant because they feel well and healthy again after their disease. This is described as the 'healthy mother effect' [17]. Although higher birth rates may be connected with a lower risk for malignant melanoma, it does not necessarily reflect a protective effect of the pregnancy, but may be a consequence of the self-selection process.

Guidelines or recommendations for counseling women who want to get pregnant after having a malignant disease are largely lacking. On the other hand, case-to-case based coun-

\section{KARGER}

Fax +497614520714

Information@Karger.de

www.karger.com (c) 2009 S. Karger GmbH, Freiburg

Accessible online at:

www.karger.com/onk 
seling seems to be fruitful, being able to take personal characteristics into account such as the women's age, stage of disease and tumor thickness, and desire to become pregnant. Most authors recommend a 2-3 years postponement of a pregnancy after a malignant diagnosis, to avoid relapses during pregnancy or shortly after, or worse, a motherless child. It is still, however, important to keep in mind that the prognosis for this disease is unpredictable.

Fetal risks of maternal cancer treatment are well described in the paper by Gottschalk et al. with a mini-review of the literature [2]. In general, treatment in the second and third trimester might not harm the fetus, but both diagnostic procedures and treatment should be thoroughly evaluated based on gestational week, the mother's health, cancer type and stage, and general diagnostic and treatment guidelines. Additionally, CT and PET (F-FDG might cross the placenta and expose the fetus to high radiation doses) should be avoided, and radiotherapy before gestational week 25 may result in fetal mental retardation [18].
The risk for placental and/or fetal metastases by malignant melanoma and fetal outcomes is also well described in the current article, summarizing known cases. For more information, the webpage about management of cancer during pregnancy, www.motherisk.org/women/cancer.jsp, might be useful.

A case-report like the one in this issue does not provide knowledge of cancer patients' outcome in general. It is, however, of great value to share the story to gain more knowledge about outcomes for fetuses that are exposed to cancer therapy. All cancer therapy provided to patients during pregnancy should be described thoroughly as studies can hardly be set up for such situations. Ideally, an international 'Cancer during Pregnancy Register' could be set up, but ethical and other restrictions are likely to interfere with such a suggestion. Collections of case series, however, in the future will be of great value and interest for clinicians, the affected patients, and their families.

\section{References}

1 Alexander A, Samlowski WE, Grossman D, Bruggers CS, Harris RM, Zone JJ, Noyes RD, Bowen GM, Leachman SA: Metastatic melanoma in pregnancy: risk of transplacental metastases in the in fant. J Clin Oncol 2003;21:2179-2186.

$>_{2}$ Gottschalk N, Jacobs VR, Hein R, Fischer T, Schneider KTM, Pildner von Steinburg S: Advanced metastatic melanoma in pregnancy: a multidisciplinary challenge. Onkologie 2009;32:748-751.

-3 Stensheim H, Møller B, van Dijk T, Fosså SD: Cause-specific survival for women diagnosed with cancer during pregnancy or lactation. J Clin Oncol 2009;27:45-51.

4 Matthiesen L, Berg G: Malignant melanoma is the most common type of cancer occurring pregnancy. Läkartidningen 1989;86:2845-2848.

5 Pack GT, Scharnagel IM: The prognosis for malignant melanoma in the pregnant woman. Cancer 1951; 4:324-334.

6 Byrd BF, McGanity WJ: The effect of pregnancy on the clinical course of malignant melanoma. South M J 1954;47:196-200.
7 Lens MB, Rosdahl I, Ahlbom A, Farahmand BY, Synnerstad I, Boeryd B, Newton Bishop JA: Effect of pregnancy on survival in women with cutaneous malignant melanoma. J Clin Oncol 2004;22:43694375.

8 O'Meara AT, Cress R, Xing G, Danielsen B, smith LH: Malignant melanoma in pregnancy. A population-based evaluation. Cancer 2005;103:1217-1226.

$\checkmark 9$ Reintgen DS, McCarty KS jr, Vollmer R, Cox E, Seigler HF: Malignant melanoma and pregnancy. Cancer 1985;55:1340-1344.

10 McManamny DS, Moss AL, Pocock PV, Briggs JC: Melanoma and pregnancy: A long-term follow-up. Br J Obstet Gynaecol 1989;96:1419-1423.

11 Wong JH, Sterns EE, Kopald KH, Nizze JA, Morton DL: Prognostic significance of pregnancy in stage I melanoma. Arch Surg 1989;124:1227-1231.

12 Slingluff CL jr, Reintgen DS, Vollmer RT, Seigler HF: Malignant melanoma arising during pregnancy. A study of 100 patients. Ann Surg 1990;211:552559 .
13 MacKie RM, Bufalino R, Morabito A, Sutherland $\mathrm{C}$, Cascinelli N: Lack of effect of pregnancy on outcome of melanoma. For The World Health Organisation Melanoma Programme. Lancet 1991;337: 653-655.

14 Daryanani D, Plukker JT, De Hullu JA, Kuiper H, Nap R, Hoekstra HJ: Pregnancy and early stage melanoma. Cancer 2003;97;2248-2253.

15 Driscoll MS, Grant-Kels JM: Melanoma and pregnancy. G Ital Dermatol Venereol 2008;143:251-257.

16 Schwartz JL, Mozurkewich EL, Johnson TM: Current management of patients with melanoma who are pregnant, want to get pregnant, or do not want to get pregnant. Cancer 2003:97;2130-2133.

17 Sankila R, Heinävaara S, Hakulinen T: Survival of breast cancer patients after subsequent term pregnancy: 'healthy mother effect'. Am J Obstet Gynecol 1994;170:818-823.

18 Pereg D, Koren G, Lishner M: Cancer in pregnancy: Gaps, challenges and solutions. Cancer Treat Rev 2008;34:302-312. 